\title{
Desert Dwellers' Meaning and Existence of Spirituality: A Gendered Case Study of Cholistan, Pakistan
}

\author{
Dr. Aisha Shoukat ${ }^{\dagger}$ and Dr. Venkat Pulla ${ }^{{ }^{*}}$
}

\section{Abstract}

Cholistan is the second largest desert of Pakistan, which is locally known as Rohi (Mughal, 1994). This paper is an ethnographic endeavour that sketches living in the desert and is about the traditional way in which people handle desolateness and powerlessness in that severely parched earth. Men and women seem to appear primordially linked to and in agreement with their environment. Their contentment is heartfelt, an aspect that seems to emerge from their belief that there is a spiritual solution for every problem. This indication forms the crux of this paper and as authors, we make a humble attempt to collate their narrative and how they make meaning of components of their living, and the importance they accord to spirituality in their lives. Deeply ingrained human and ecological values in life include contentment and presence of spirituality within their life surrounds that allows them to sing an ode of gratification to nature. This article presents evidence of adoption of spirituality as resilience and its effect on the emotional wellbeing of the desert dwellers. In our discussion, we present the evidence to suggest that spirituality has strengthened and enhanced resilience of the people for coping with the adversities of the lifecycle in a rather hostile environment of Cholistan.

Keywords: Spirituality, Women, Desert, Cholistan, Resilience, Ethnography, Pakistan

\footnotetext{
${ }^{\dagger}$ Lecturer, Department of Social Work, The Islamia University of Bahawalpur, Pakistan, Email: aisha.shoukat@iub.edu.pk

Corresponding Author

I'Senior Lecturer in Social Work, Australian Catholic University, Brisbane, Australia, Email:Venkat.Pulla@acu.edu.au; dr.venkat.pulla@gmail.com

(C) 2017 Shoukat and Pulla. This is an Open Access article distributed under the terms of the Creative Commons Attribution License (http://creativecommons.org/licenses/by/2.0), which permits unrestricted use, distribution, and reproduction in any medium, provided the original work is properly cited.
} 
Introduction

The desert can be mentally trying even when the body is not under duress. Quite often the horizon is a straight line. Indistinguishable washes, endless plains, the hot wind. Nothing to cling to. Nowhere to go.

Figure 1:The Spiritual Desert

Source: (Comins, 2016)
The statements of Comins (2016) in Figure 1 illustrate the life of the people in deserts. This research is an attempt to paint the meaning and existence of spirituality of desert dwellers of Cholistan, Pakistan. It is believed that Cholistan perhaps had more water than any other desert within Pakistan. Currently, it seems that Cholistan is haunted and renowned as the nomadic people that create songs to express their longing for water and these melodies bear witness that water was once present. 'In one desert melody, a river surges into the Indus at a place called Pattan Minara, the site of an ancient Buddhist monastery, now just a spindly stone structure - this is the lost Hakra River, the sacred Saraswati extolled in the Rig Veda, Hinduism's third great river, which researchers now agree is more than just a stubborn myth' (Kohari, April 25, 2015). This paper is part of a project on Desert Spaces, People, and Spirituality and hope (Pulla, 2017), which are part of a series on the role in which 'hope' plays key role in tyrannising terrains. The central theme of the current paper is to focus on spirituality and how this has strengthened and enhanced resilience of the nominated people for coping with the adversities of their life in such unreceptive environment. We have adopted rather commonly constructed definitions about resilience such as hardiness, resourcefulness, and mental toughness (Pulla, 2013). Equally, it is wiser to look at resilience as a dynamic process whereby individuals and communities exhibit positive behavioural alternation when one encounters major adversity, trauma, tragedy, threats, or even considerable sources of stress (Pulla and Mamidi, 2015).

It is in this context, the authors attempt to capture the expression, perception and worldview of the women living with their families in challenging conditions. In this paper, we explore the existence of spirituality beyond conventional religions - Hinduism and Islam amongst nomadic people of this desert region. In our observations and ethnography, spirituality, we have gained and befitted the upmost authority to encounter the daily social problems in Cholistan. Divine symbols, personalities, and remedies emerged as the solution to some of their problems although such measures at times, resulted in adoption of superstitions, possibly detrimental to gaining further appropriate solutions. Most commonly, resilience is understood as positive adaptation despite adversity (Pulla, 2013). Authors have taken into consider the presence of 'some demonstrable substantial risk' (Fleming and Ledogar, 2008: 47-64) to be essential variable in making resilience operational. Thus, a natural capacity to navigate life well in harsh climates may also depend on certain other aspects from the realm of culture such as religion/spirituality. Hypothetically, evidence 
suggests that spirituality and religion promote or hinder certain psychological virtues that increase resilience (Pulla and Mamidi, 2015; Pulla, 2014; Woods and Pulla, 2016).

Habitats in hostile environments with minimal infrastructures and remote from governments are hardly talked about. It is intriguing how the desert is the only landscape defined by what it lacks and yet, as we stroll through deserts, the thought of water is set aside? (Kohari, April 25, 2015). Without exception the desert dwellers survive, and seek life in those challenging ecological terrains. Water so essential to life this is cliché praise than a Cholistani 'dahar', the mud flat in which the families live, in this beautiful desert landscape. The location map of Cholistan is shown in Figure 2.

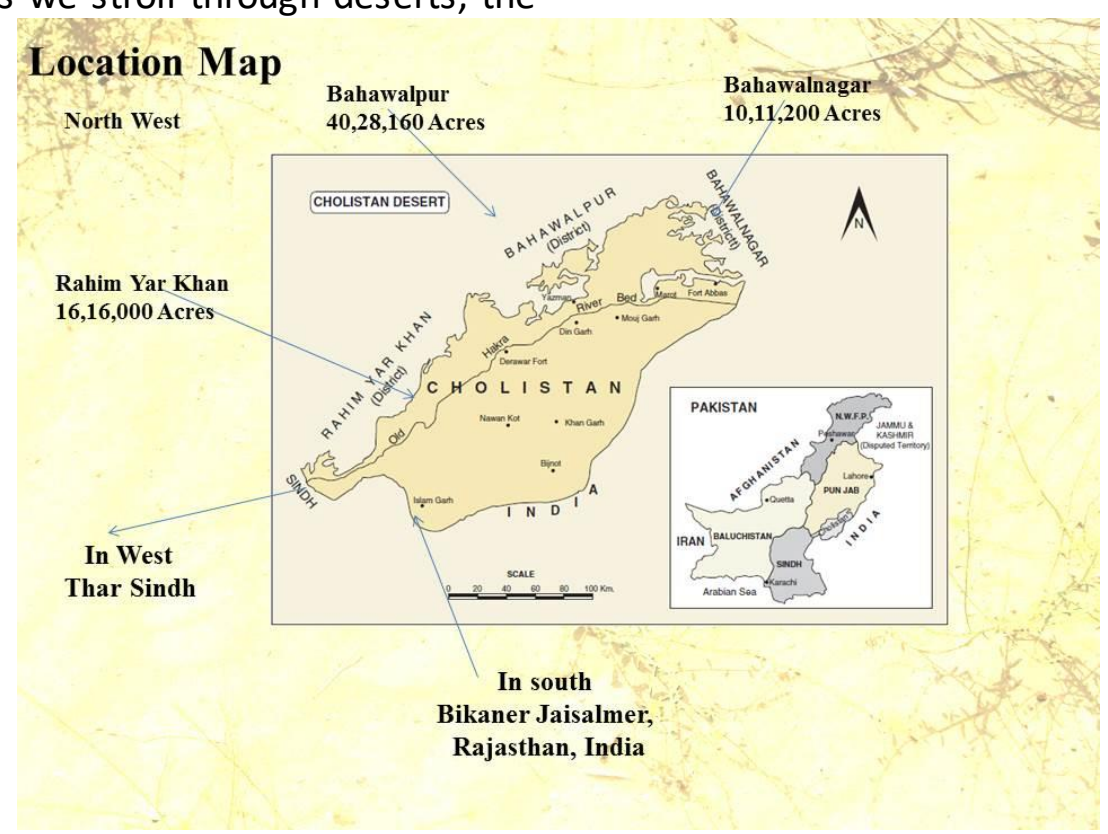

Figure 2: Location Map of Cholistan

Our research informs how women view their environment and their daily chores, a possible fait accompli in those conditions. The long drawn tribulations of women include walking miles for a vessel of water and performing several gendered roles within the communities. This observation is similar to the hill economy where women and girls ramble over the hilly landscape to collect fuel, food and water from distant places everyday (Singh, 2014; Singh, 2015a, 2015b; see also, Bhattacharyya, 2015). The arid climate of Cholistan (Ali, Chaudhry and Farooq, 2009) contributes to a near deafening desolateness in resolution of life's concerns, that for many women a solace in a visitation to the holy Dargah (Shrine) is just good enough and for many it could even be a dream to visit. Research has established connection between spirituality and resilience. Indeed, there is a suggestion that modern western cultures have become neglectful of family and thereby, reduce opportunities for children to acquire spirituality and resilience. Benson and
Thistlethwaite (2008) argued that communities in the West have become focussed on perfection and fail to view pain, suffering, mistakes and failure as normal components of life. Both Western and Eastern writings provide a personal and intimated meaning and purpose of the spirituality presence. This seems to be expressed as a profound relationship with the self and of others, the need for meeting individual vis-à-vis of the community needs (Zapf, 2005).

Distinctions between spirituality and religion is seen in numerous writings (Zapf, 2005; Canda and Furman, 2010; Oxhandler and Pargament, 2014; Pulla, 2014). In Cholistan, no such distinction is demarcated between the religious beliefs and spirituality orientation.

As authors, we are concerned that the Western literature on spirituality to humanity seems to subscribe to a dichotomous approach where religion and spiritually are discussed often separately. It appears that a tendency to 
perceive religion as an observable expression of a belief system via a set of activities that are often prescribed, whilst spirituality seems to be more internal, heart-centred or even possibly an aligned concept, as it persists (Pulla, 2014, Zapf, 2005, Canda and Furman, 2010). It has been said that there are four considered contours that delineate four aspects of spirituality that is, belief in God, search for meaning; mindfulness; and a feeling of security from within the self (Hardt, Schultz, Xander, Becker, and Dragan, 2012). Spirituality seems to be defined the way in which the people of Cholistan find solutions for their problems and several of those solutions that they draw upon are and do not seem to be supported by the belief systems within the mainstream religions that prevail in the desert region, that are, Islam and Hinduism.

\section{Methodology, Scope and Objectives}

In this article, we report from an ethnographic study (Hannerz, 2003; LeCompte and Schensul 2010) $)^{1}$ of the people of Cholistan, their life and living in a desert climate. The term 'ethnography' refers to a descriptive study of people and their culture in local habitats (Hannerz, 2003; LeCompte and Schensul 2010). As an investigation of culture and social life this is achieved through direct empirical fieldwork through methods such as participant observations and largely open-ended interviews (Hannerz, 2003; LeCompte and Schensul 2010; Robben and Sluka, 2007). The ethnographer writes about the routine, daily lives and chores of people, including the predictable patterns of human thoughts and human behaviour (Fetterman, 1998; see, Bhattacharyya, 2016; Bhattacharyya and Singh, 2017). Within this enquiry, women within the age group of 40-65 were recruited through snowball sampling technique. The research design received ethical clearance from the Islamia University of Bahawalpur. Additionally, interviews with the inhabitants and participant observation were used as additional tools in

\footnotetext{
${ }^{1}$ See for examples of recent ethnographic studies by Bhattacharyya (2016) and Bhattacharyya and Singh (2017).
}

order to gain deeper understanding in the two geographical units - lesser and greater Cholistan. However, due to lack of availability of latest Census data, we had to stick to 1998 Census data. Nonetheless, some of the key questions used in probing about life and living circumstance include as to how spirituality is so intertwined with their life and struggle in Rohi. In other words, the research delves at women's capacity to handle desolateness and powerlessness in the midst of severely parched tobas within the terrain.

\section{Topography of the Region and the Tobas}

The Cholistan is the second largest desert in Pakistan (Figure 2) and geospatially located in the subtropical region in between the latitudes $27^{\circ} 42^{\prime}$ and $29^{\circ}$ North, and the longitudes 69o

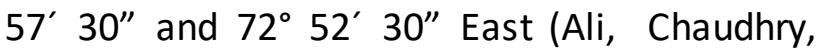
and Farooq, 2009). It is located at 112 meters above the mean sea level and the temperature can flare up to $50^{\circ} \mathrm{C}$ in the summer season (Ali, Chaudhry and Farooq, 2009). It is also known as Rohi (Mughal, 1994) and is the hottest desert in Pakistan (Geyh \& Ploethner, 1995). The climate of Cholistan is harsh with severe weather conditions in both summer and winter (Mughal, 1994). Its evapo-transpiration rate is considered high at 300 centimetres per annum (Ahmad, 2005), though, at times, winds of Persian Gulf lean towards it and can create thunderous storms (Khalid and Gilani, 2009), but it is still a sandy desert with an average yearly rainfall of $100-200 \mathrm{~mm}$. The population of the desert is estimated at 0.155 million \{Cholistan Development Authority, 2015 (CDA)\}.

Length of the Cholistan is 480 kilometres, and breadth ranges from 32 to over 190 kilometres from different places (Akbar, Khan, \& Arshad, 1996). Based on its geographical features, Cholistan is divided into two parts -greater and lesser Cholistan (Akbar et al., 1996), and it is a part of three districts of Bahawalpur division. Throughout the year, the seminomadic movement of the people are dictated largely by the presence or absence of water and fodder. People tend to cope with the limited and basic amenities and the women in 
general are socially less aware and illiterate (Khan Rashid and Sarwar, 2004). Cholistan consists of Bahawalnagar, Bahawalpur and Rahim Yar Khan, which constitute the three rural districts and are designated electoral constituencies for federal or provincial elections. There is a small community of people called Lali belonging to Jat clans that lived for centuries as pastoral tribes. It is believed that the Sufi saint Mian Muhammad Siddique Lali was one of them, therefore the tribe received a status amongst the tribes in Cholistan (Shoukat, 2016). The Table 1 presents the district population in its three constituencies. The economic development and welfare services seem to be neglected. Figure 3 highlights the different types of housing. The desert dwellers seem to be treated as a scattered, inconsequential vote bank (Kohari, 2015).

\section{Table 1: Cholistan Population and Female Literacy}

\begin{tabular}{cll} 
& Area & Area 8878 Sq.Kms \\
& Total Population & 2061447 \\
Bahawalnagar district & Female Population & $48.22 \%$ \\
& Female Literacy & $23.00 \%$ \\
& Male Population & $51.78 \%$ \\
& Male Literacy & $46.00 \%$ \\
\hline \multirow{3}{*}{ Rahim Yar Khan district } & Area & Area 11880 Sq.Kms \\
& Total Population & 3141053 \\
& Female Population & $48.00 \%$ \\
& Female Literacy & $22.00 \%$ \\
& Male Population & $52.00 \%$ \\
& Male Literacy & $43.00 \%$ \\
\hline \multirow{3}{*}{ Bahawalpur district } & Area & Area 8878 Sq.Kms \\
& Total Population & 2061447 \\
& Female Population & $48.22 \%$ \\
& Female Literacy & $23.00 \%$ \\
& Male Population & $51.78 \%$ \\
& Male Literacy & $46.00 \%$
\end{tabular}

\section{Source: Pakistan Census, 1998}

Human and animal lives depend largely on rainfall for survival and sustainability in Cholistan. Precipitation is a major source of water in Cholistan because underground water is saline in most of the areas (Akram, Kahlown and Soomro, 2008). The remainder of water sources are dependent on storage of rainwater in man-made ponds and wells locally known as toba (small ponds) and kund. Figure 4 is an attempt to reflect such irregular water bodies. The irregular rainfall, thus, play a vital role in the life of Cholistan, as they deposit water in tobas used for drinking, washing and quenching the thirst of their farm animals. These tobas are the only source of water for all life within the area. It is for this very reason that major portion of the population move like gypsies. When a toba dries out, they move to the next destination and commence searching for yet another water-filled toba signalling that life is very challenging and requires myriad efforts for survival.

In fact, life revolves around the search of water. Although rainfall is minimal in Cholistan, yet, it gives meaning and colours to the life activities. Local people and livestock are dependent on rainfall from vegetation to food and fodder throughout the year. Scarcity of water coupled with deprivation from basic facilities in the hostile environment of the desert has given a unique way to life of the inhabitants of this area. 


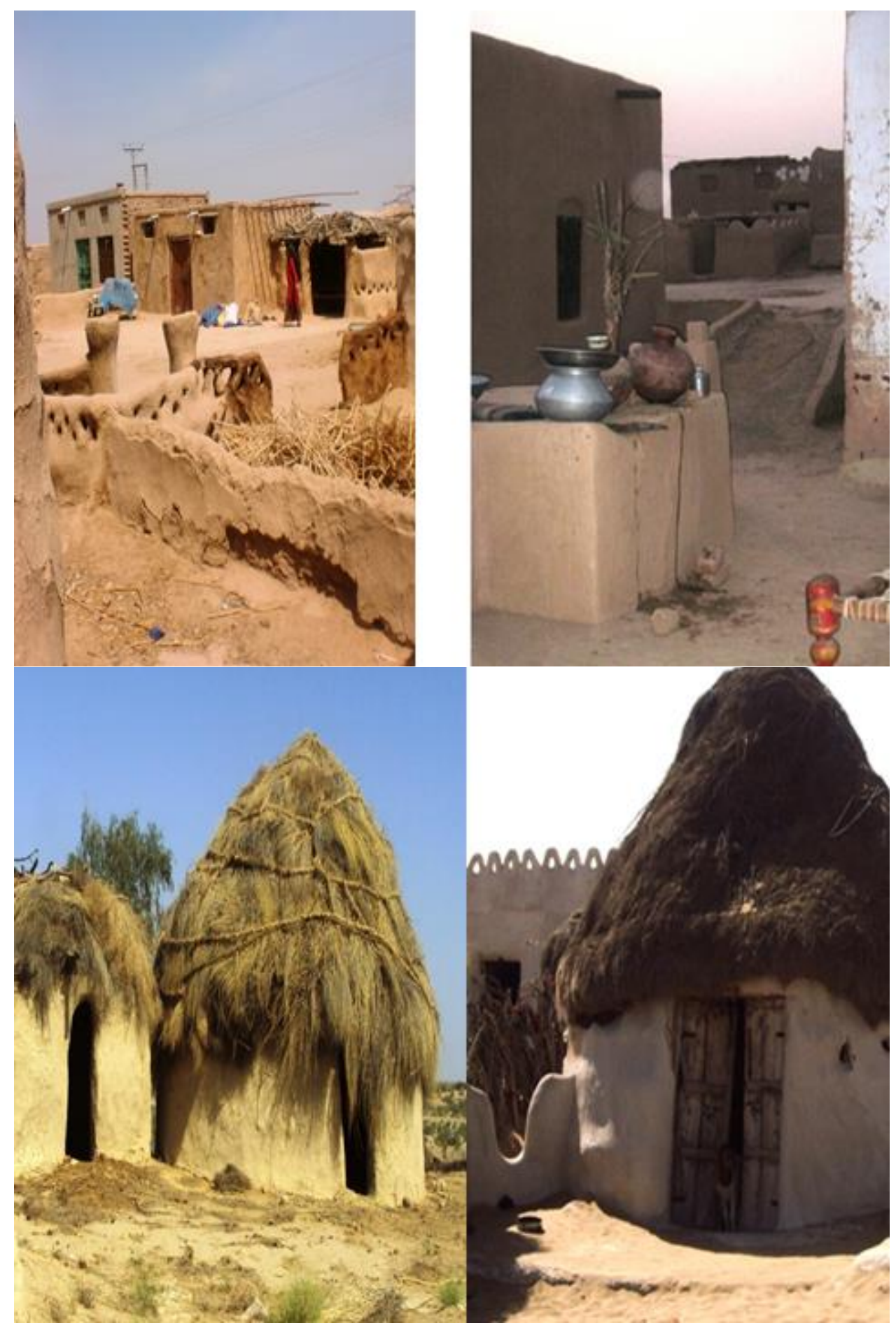

Figure 3: Different Forms of Housing in Cholistan 


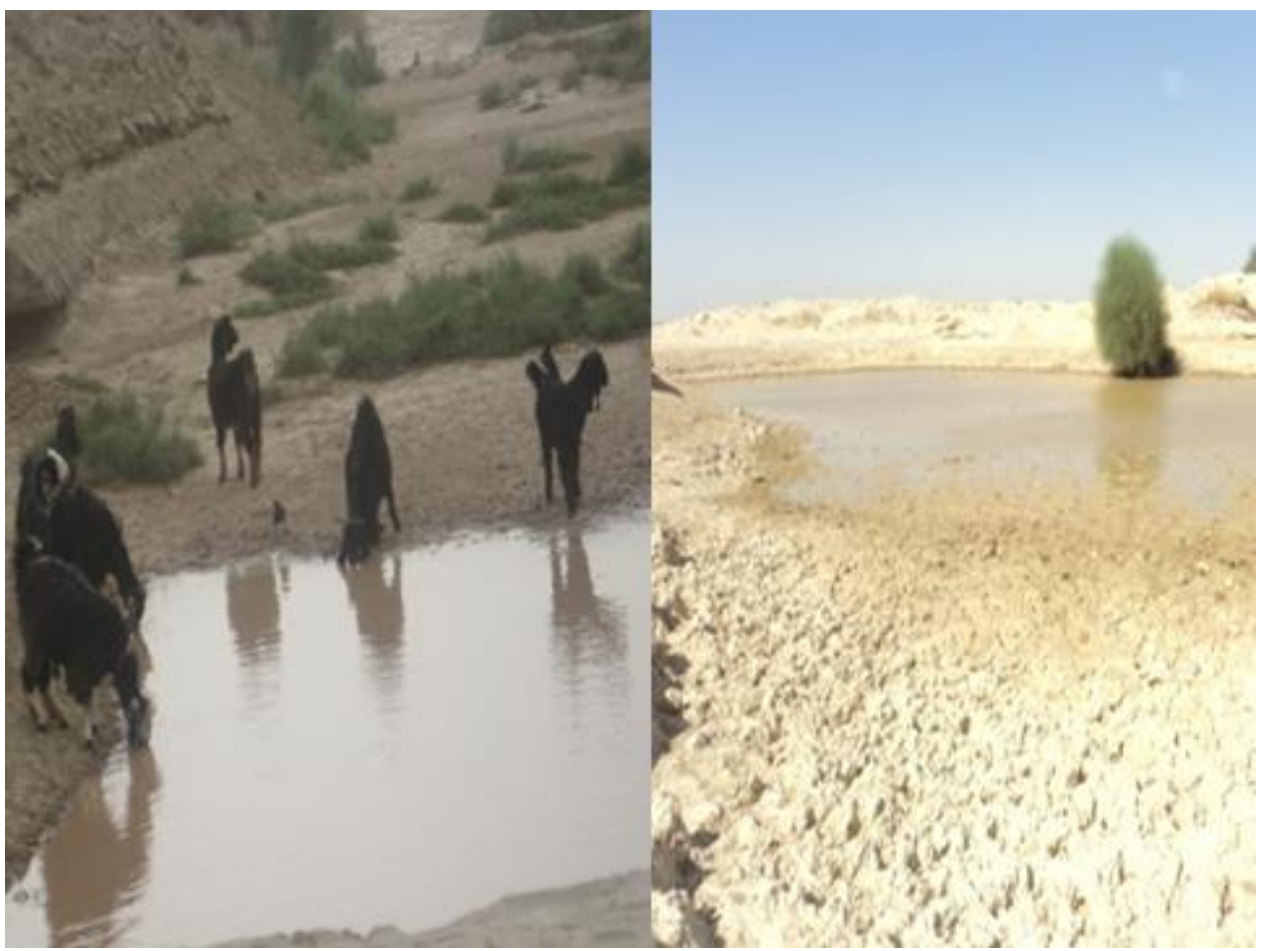

Figure 4: Irregular Ponds

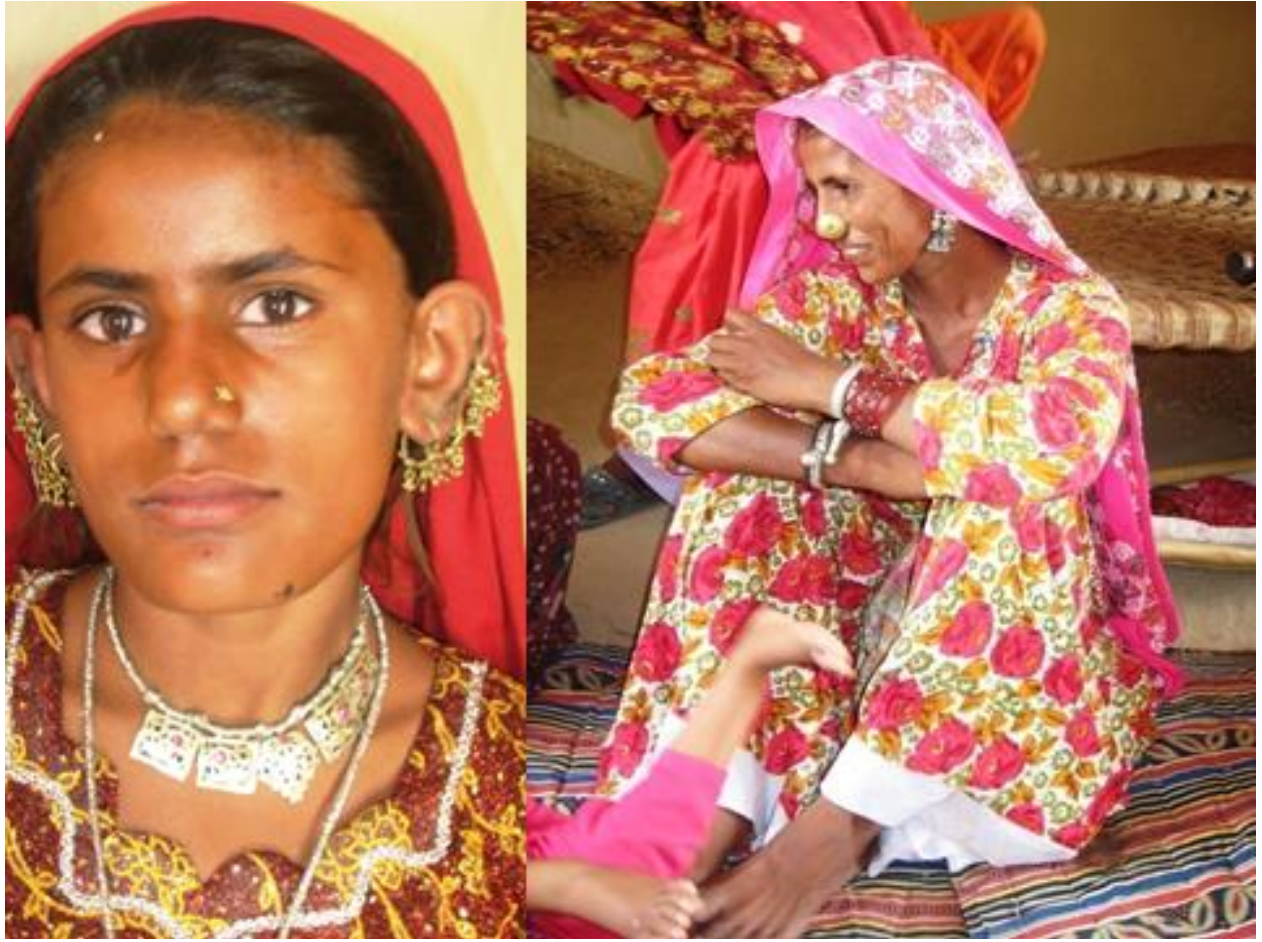

Figure 5: Women of Cholistan

\section{Women and Desert Spirituality}

But in a melody, a poet tries to reason with a river, imploring it to calm its raging waters and let him make his way across. Only if you write me a poem, replies the river coyly. So that the world remembers me when I'm gone. (Kohari, 2015)

Nevertheless, where is the river? Where is the water? The desert dwellers appear to be primordially linked to and in agreement with their environment and heartfelt contentment seem to emerge from their belief that there is a spiritual solution to every problem, including times when there is no water left in the tobas. As this forms the crux of this paper, we make a modest attempt to surface the meaning of such and other statements through the help of the narratives of the women of Cholistan. Their values in life such as contentment and presence 
of spirituality in their life circles allow them to sing an ode of gratification to nature. We extend the evidence of adoption of spirituality as resilience and its effect on the emotional wellbeing of the desert dwellers. Women in our study seemed categorical that they have evidenced that spirituality has strengthened and enhanced resilience of their community's coping mechanisms against the adversities of their life in a rather hostile environment of Cholistan. People living close to the Dargah could view any differences between spirituality and religious beliefs:

The whole point is purposeless; there is no need to pursue the distinction between the two, as they are both sides of the same sikka (coin).

Women in Cholistan (Figure 5) believe survival as one of the biggest achievements in tough geographic conditions amidst the desert climate. Living under these harsh conditions, they assertively declare that they receive their psychological and social strength from spirituality, which makes them satisfied despite the intensity of their everyday struggles. One of our respondents declared that prayers and spirituality offer the necessary values to balance their living.

Makes you feel contended.

Feel satisfied.

Feel that someone up there is still looking after us.

Surrender to the will of God.

His will is guided by wisdom.

He will decide what to bestow upon you or me

\section{The Chanan Pir $^{2}$}

Before we introduce the legend of the Channan Pir (Figure 6), it would be important to consider that Pakistan's primary religion is Islam, while the next substantial population are the Hindus (PBS, 1998). Pakistani Hindus many of them have clearly a descent in Pakistan, constituting

\footnotetext{
${ }^{2}$ Pir means religious mentor
}

around 2\% of Pakistan's population. The legendary history suggests that in the $13^{\text {th }}$ century, a red-cloaked fakir (saint) from Uch Sharif, was wandering away into the desert kingdom of a Hindu ruler, Raja Sadharan. It is said, that the saint or fakir advises to the Maharajah, to embrace Islam. However, the Maharajah refused but his queen apparently sought the fakir in privacy and urged him to use his holy powers to gift her child. The legend continues on that the fakir spoke: "You will have a son, but he shall be a Muslim". When the prince was born, his beauty won him the name of Channan, meaning moon in the local language. In a twist of fate, while still a child, Channan started reciting the Kalma. ${ }^{3}$ As word spread about the crown prince's different faith, his political reputation was brought to an abrupt ending. The King immediately ordered the execution of his son but on the Queen's intervention (Wordpresscom, 2017) resorted to exile him. He was packed into a box of sandalwood and sent away into the deeper part of the desert. Interestingly, this precious child was nursed water and food by a donkey. Soon after, people began flocking towards him to seek his blessings. People preserve pouring into the Channan Pir Dargah particularly on Thursdays and many of them bring gifts to share - sacks of wheat and even goats, particularly when their mannat (prayer) is heard. Women and men also tie coloured threads around the Dargah as mannat (Figure 7). Women explain that Channan Pir is their hope, their living legend. A prayer here or even from far will take care of their pain and suffering. Women living in Cholistan have to perform multiple chores, at home - cooking food, caring for children, fetching water from a nearby toba and collecting wooden fuel for cooking food.

\footnotetext{
${ }^{3}$ It means a word, saying, part of speech, the Muslim confession of faith
} 


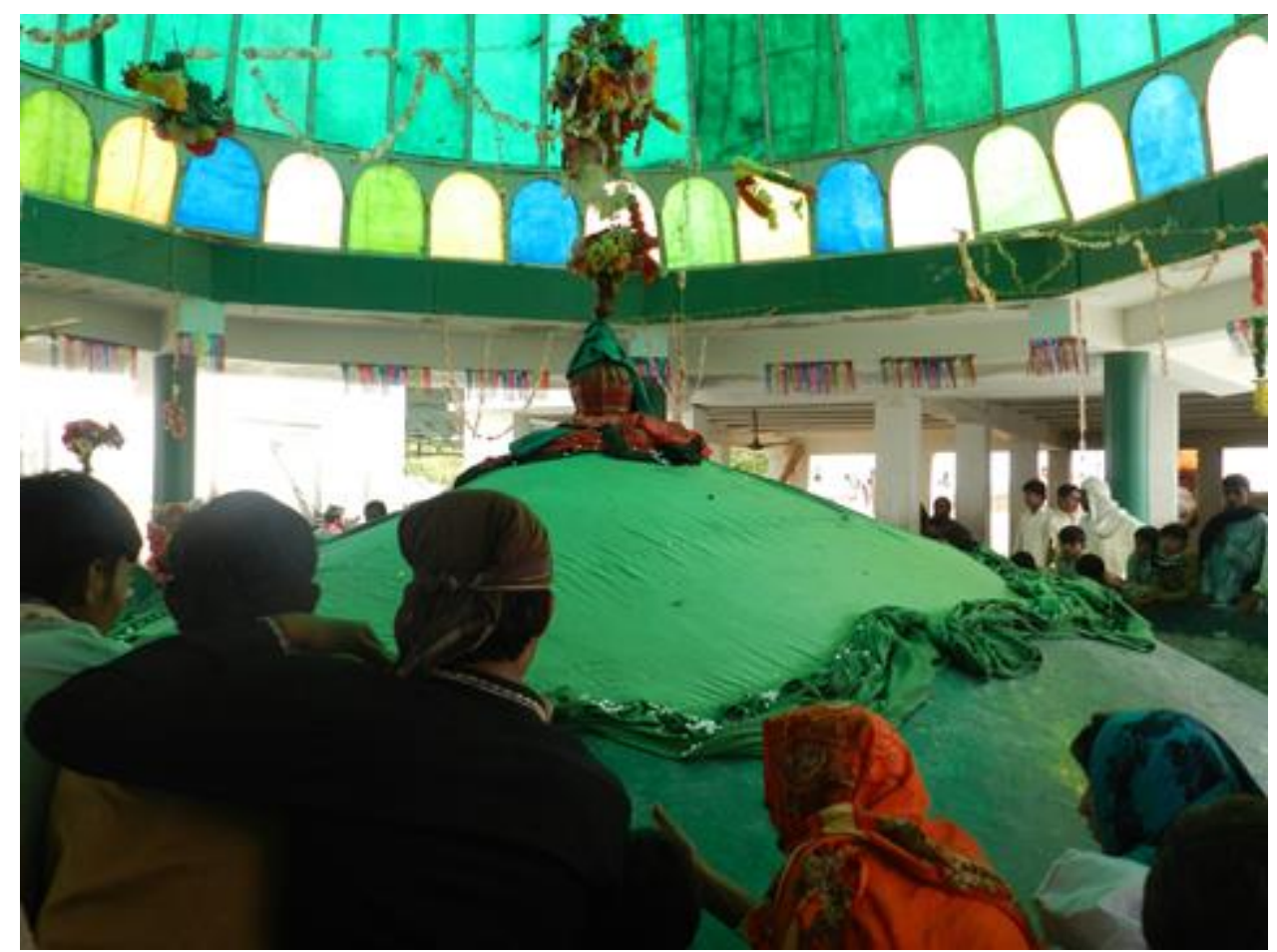

Figure 6: A View of the Inside of the Channan Pir

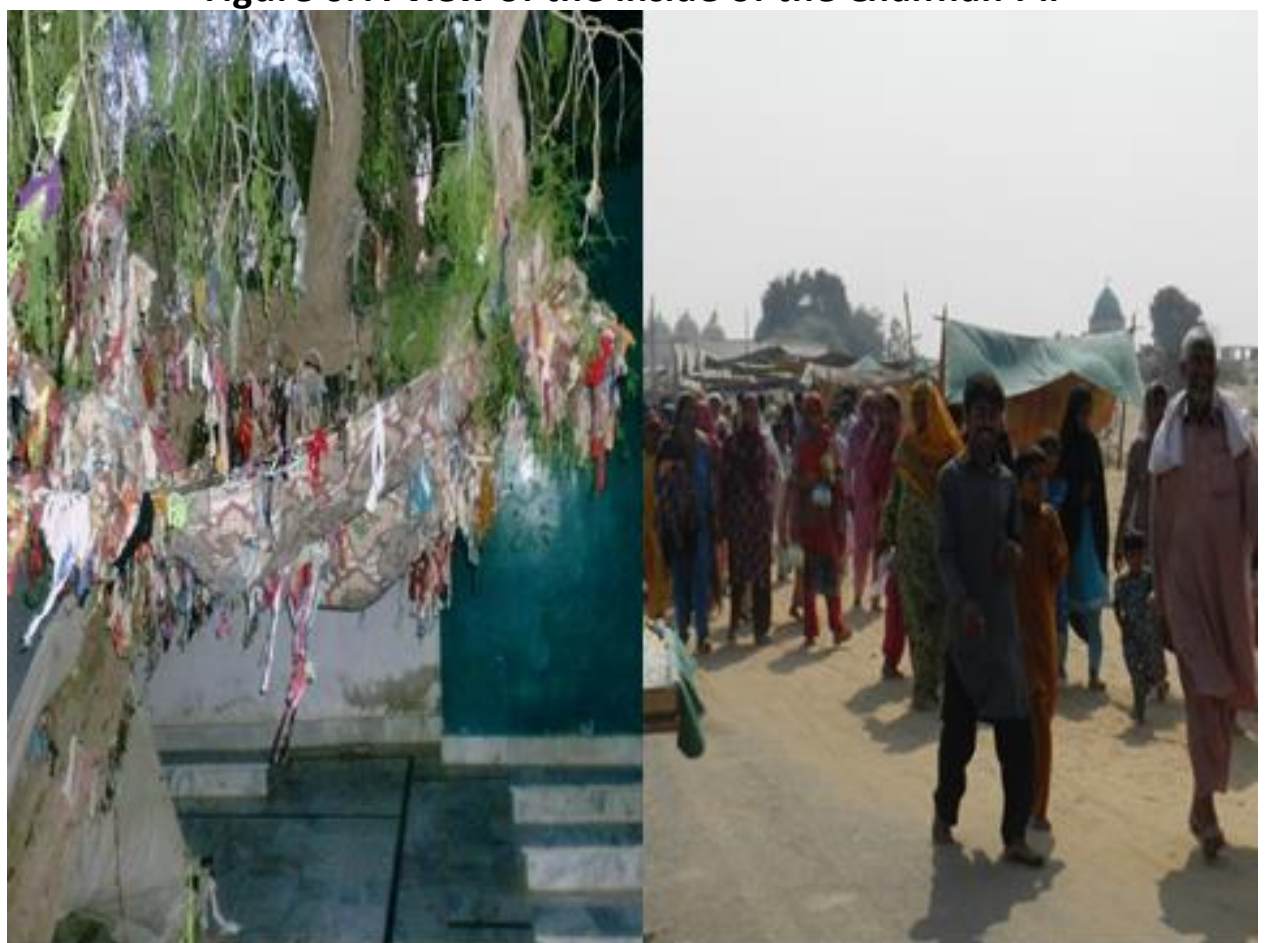

Figure 7: Women and men tie coloured threads around as mannat in Channan Pir Dargarh

Likewise, outside their home too, they help and economically in comparison to men their men in animal husbandry, cultivation and (Farooq, Muhammad and Munir, 2007).

work as labourer in the fields of farmers within the settled areas (Soharwardi, Ali and Arshad 2011). This finding further bears resonance to previous literature on hill economy (Singh, 2014; Singh, 2015a, 2015b). As stated above, women living in Cholistan are not literate and skilled; hence, they are more backward socially

In the absence of basic facilities such as, potable drinking water, sufficiency of food, health, education and shelter, dwellers derive their psychological satisfaction from spirituality and religiousness. Tacey (2003: 28) narrates spirituality as "the careful and reflective art of developing a relationship with the sacred." Often there are different interpretations and 
sometimes overlapping meanings and orientation of the concepts of religion and spirituality (Narayanan, 2009). Krok (2008) asserts that spirituality is deeply linked to religion. However, spirituality in psychological terms is more accepted and understood as a concept that appeals universally to all people irrespective of any religious beliefs. It appears to offer a positive approach and an attitude towards transcendence and allows them to be hopeful about their life.

\section{Cultural Geography and Spirituality}

It is interesting to note that cultural geographers have attempted to analyse the deep impact that natural landscapes have on the human mind (Lane 1998; McDowell 1999). They offer valuable insights that help our understanding of the relationship between habitats and people. They suggest that some physical landscapes stimulate in human beings as an inspiration or an awakening that may eventually lead to their 'completeness'. Thus, the desert climates offer an infinite possibility:

The only centre is the centre within, and so one looks inward. The desert is a place to become as straight as the horizon, as sharp as a thorn. Learn to live with little. Learn to live in light so bright that nothing in your soul can remain hidden. Learn to live at risk.The contract reads: courage required. No exceptions. (Comins, 2016)

Horton (1984) suggests that religious institutions are society's important systems that impart beliefs and practices, which overtime are carried on for generations. Generally, they are not contested, and seem to appeal to people in broad terms. The followers in general do not take them to be untrue. Religion includes system of beliefs and practices which describe relationship of sacred and the mundane (Ferris and Stein, 2008). Certainly, in the Cholistan, the people's spirituality is beyond formal religion and it is their immense trust in the desolateness, the tranquillity, the sand and the sun, and their acceptance of everyday events that the good and the not so good, the bad and even the cruel in their life is something to be accepted, as is.

Klemm (2004: xiv) states, "desert is a space where humans go to encounter themselves, their demons, and their god. The desert is at once an oasis, a paradise, where humans renew themselves and are transformed". In the light of this description of the desert, inhabitants of Cholistan have attained the point where they are close to nature in discovering their relations with unseen power of nature and 'self'. The dwellers of the Cholistan continue to lead their life in semi nomadic culture where they migrate from one place to another in search of water for them and their animals.

Since there are very fewer earning opportunities for the people of Cholistan (Shoukat, 2016), women are seen to undertake tending of animals exclusively in Cholistan as their families are dependent on herding and grazing camels, cows, sheep, and goats reared for selling, milking, and shearing their wool. It is documented that almost half of Pakistan's population consists of females, and they contribute about $74 \%$ in the agricultural sector, and a substantial section of this population living in rural areas is illiterate (Government of Pakistan 2009; Shoukat, 2016). Cholistan is no exception to this as it lacks in basic infrastructure and facilities for accessing education. Women in general lag behind in many ways (Khan and Khan, 2015). One participant wisely summed up:

How do we explain that we do not have cash to survive? Or all those facilities that you have in your towns. We do not have power (electricity for most of us). We do not have water, but I think we are okay in our own way. Living here makes acceptance of the supernatural powers. Those powers are a source of contentment and patience.

The most important concern of the people in Cholistan is sustaining life in the desert with scarcity of water. As stated earlier, when one water source (toba) dries out, the whole family/clan moves to another place in search of water. Hence, life of the Cholistan dwellers is 
characterised by pastoralism and people keep on migrating from one place to another in search of water for themselves and their cattle (Akbar, 1996). Under these circumstances, spirituality answers to their questions and solutions to the problems. There seems to be three ways of understanding spirituality from the perspective of the desert dwellers:

- Related and influences by mainstream religions - Hinduism and Islam, prevalent in Cholistan.

- Free or rather extended practice akin to Sufiism through acceptance of the Pirs and their sayings.

- The people and their outlook towards the terrain and ecology, their blind faith in the surroundings that it is hearing them and it will respond.

It is the third type of spirituality that appears very much people centred and humanistic focusing on human attainment despite adversities (Hill et al., 2000). As a community they live in harmony, they care about their neighbours, just in the same way they adore the almighty, the supernatural. Their love of God, it seems is more in reverence and recognition that there is nothing in their capacity, but:

There is in the capacity of God, and what he sends in his own time. There is no reason, there is mystery, and how will you be in harmony, if you are not even in harmony with the drying of Toba?

In Cholistan, it appears that major orientation of spirituality derives from their ecology: the ever-present harshness of weather and physical hardships and the fact that they need to move in search of water, from one toba to the other. They seem to take to prayer as the deeper impulse contained in their belief that the spirituality as they trust is right in the desert. The desert possesses truly a number of blessings. Unwilling they remain to leave their habitat because of their firm belief in those divine blessings, expressed in these words:
Rohi wich dhair barkat aey (There is a great blessing in the Cholistan.)

Indeed, Cholistan is a spiritually alive entityexpressed as:

\section{Meenh wasy tey rohi wasdi aey}

Rohi flourishes with the rains. They do not consider just a 'deserted area' rather they see it as sacred Rohi. Their spirituality-induced resilience provides them with emotional stability against many of their problems and hardships including in case of severe death of a near one without the medical treatment, they relate death entirely as the willingness of God. They say:

Jeho Allah di marzi aey (We are happy with what is Allah's will.)

The feelings of satisfaction, after such a loss, are due to their belief in God that every happening is only with His order and will. The findings of Krok (2008) also endorse that spirituality appears to be an essential motivational force that creates a strong effect on people's thoughts, emotions, and behaviours.

As mentioned above, women in Cholistan experience spirituality in a myriad of ways. For all of their financial, psychological, or health concerns they visit a pir, or dargah for making verbal vows, or tie up cloth strip with trees located near the shrine. Their belief is that, by knotting a cloth strip they have passed on their problems to the holy saints for resolution and they need not to put in any further effort. They implicitly believe that their worries will be taken care of. Women also explicitly follow all instructions of Pir without indulging in any analysis of the Pir's instructions and the true relationship with religious teachings and rituals. Women do not offer obligatory practices of the religion such as offering prayer and fasting, but worship Pir and think of them as divine and miraculous personalities. While prayer appears in every religion, Cholistan women communicate with Pirs and consider them as messengers of God. Their spirituality trans ports them beyond religiosity such as; both Muslim and Hindu visit the same shrines of famous Sufi 
saint Channan pir in Cholistan. In India and Pakistan, both Hindus and Muslims visit the Dargahs. During the festivities Channan Peer Urs, (procession) Camel Journey, Camel Dance, Ox Running, Jeep Rally, Cultural Night programme (folk music programme) and Firework Show. The Channan pir becomes one of the most popular pilgrimages for the people that travel from southern Punjab. Both Hindus and Muslims participate in spiritual activities and offerings after their 'mannat' from previous years - some come to tie a cloth on the tree and hope to return when their mannat is fulfilled (please refer to Figure 7). Some ask for a boon. Leave a petitionary prayer. As for a son. The following year they return to open the thread or cloth from the tree that they have tied. Both Hindus and Muslims make donations, feast and feed and make provisions for charity in the name of God. This is how the song and the legend of Channan Pirare kept up and each year it results in theatre performances and musical shows. The festivities bring magic, dancing magic shows, farm animal rides, camel show, local jewellery and handicrafts to light and is an opportunity for people beyond Bahawalpur to visit.

Most of those who visit on a Thursday and stay overnight and leave on a Friday morning after a magical night on the sand dunes under the wide-open sky are the luckiest ones to experience the unique benediction of the Channan Pir Dargarh. The area is about $65 \mathrm{kms}$ from Bahawalpur.

In the context of the environment, the researchers observed that women have a strong tendency towards spirituality in the desert of Cholistan. The existence of supernatural powers in their coping with the problems in daily life makes them formulate more vows as compared to men. During interaction with the women respondents in Cholistan, they expressed their deep wish to visit the shrine of Channan Pir. The only purpose to visit the shrine is for formulation of more vows or to pray, to thank for fulfilment of any previously made wish. A woman explained:
Zaleen piraan ko dhair manedyaann neyn (We have more interest in pir and amulet, and as women are not hesitant to admit this clearly that we seek the spiritual healer. We do not seek him for.)

\section{Conclusion}

Overall, spirituality has perceptible effects on the life of people of Cholistan and serves as resilience for coping with the difficulties of their life. The feelings of spirituality have instilled contentment and resistance. They appear to find new ways and practical solutions for their problems. Krok (2008) refers to spiritual coping as a relationship with one's own self, and with others, and with the sacred/God or even nature. This notion resonates behind coping strategies that reflect their search for a meaning, purpose, and hope, in their life in Cholistan desert.

Clearly, this ethnographic spirituality remains the first port of call of the women. Unseen to the naked eye, the power of spirituality is the only motivational force that makes men and women resilient, and their survival in an environment that has sparse resources. While there may not be unanimity upon the relationship of religion, spirituality and religiosity, scholars accept that both spirituality and religion are inter-related, albeit some scholars opine that spirituality is not necessarily dependent on religion. In the case of Cholistan, the later concept comes alive, as women living in the Cholistan are not necessarily devout Muslims or Hindus. Neither are practicing Muslims nor practicing Hindus. Yet, they are spiritual. Leaving it to God, the Pir and the universe provides a major source of satisfaction and solace from pain and problem. Cholistan women cope with odds of life with contentment and patience and gratitude to the desert. In their words, 'after every turbulence and disruption that unseen power enables them to revert to their normal chores of the daily life'. 


\section{References}

Akbar, G. A., Taj, N. K. and Ashraf, M. (1996). Cholistan desert, Pakistan, Rangelands, 18, (4), 124-128.

Akram, M., Kahlown, M. A., and Soomro, Z. A. (2008). Desertification control for sustainable land use in the Cholistan Desert, Pakistan - the future of drylands, Verlag: Springer 483-492.

Ali, I., Chaudhry, M. S. and Farooq, U. (2009). Camel rearing in Cholistan desert of Pakistan. Pak. Veterinary Journal, 29 (5), 85-92.

Ahmad, F. (2005). Agro-pastoral systems in Cholistan, Pakistan Geographical Review, 60,(2), 65-69.

Benson, J. and Thistlethwaite, J. (2008). Mental health across cultures. A practical guide for health professionals. Oxford: Radcliffe Publishing.

Bhattacharyya, R. (2015). Working childhoods: youth, agency and the environment in India, Progress in Development Studies, 15(3), 292294, DOI: 10.1177/1464993415578570

Bhattacharyya, R. and Singh, S. (2017) Exclusion (and seclusion): geographies of disowned widows of India, GeoJournal, 1-18, DOI: 10.1007/s10708-017-9800-0

(Publisher: Springer)

Bhattacharyya, R. (2016). Living with Armed Forces Special Powers Act (AFSPA) as everyday life, GeoJournal, 1-18, DOI: 10.1007/s10708016-9752-9

Canda, E. R. and Furman, L. D. (2010). Spiritual diversity in social work practice: the heart of helpin (second edition). New York: Oxford University Press.

Comins, M. (2016, no-date). The spiritual desert. [Weblog]. Retrieved 21 December 2016, from http://www.torahtrek.org/appwritings/writing-4-the-spiritual-desert

Cholistan Development Authority, (2009). Office Record (unpublished)

Farooq Umar, Iqbal Muhammad and Ahmad Munir (2007). Livestock farming in Cholistan desert of Pakistan: setting the development strategies. Annals of Arid Zone, 46, (1), pp. 111132.

Fetterman, D. (1998). Ethnography: Step by step (2nd ed., applied social research methods series v. 17). Thousand Oaks, Calif.: SAGE.

Ferris, K., and Stein, J. (2008). The real world: an introduction to sociology: New York, W.W. Norton.

Geyh, M., and Ploethner, D. (1995). An applied palaeohydrological study in Cholistan, Thar Desert, Pakistan. International Association of Hydrological Sciences, 232, 119-127.

Hannerz, U. (2003). Being there... and there... and there!: Reflections on Multi-Site Ethnography, Ethnography, 4(2), 201-216, DOI: $10.1177 / 14661381030042003$

Hardt, J., Schultz, S., Xander, C., Becker, G., and Dragan, M. (2012). The spirituality questionnaire: core dimensions of spirituality. Psychology, 3(1), 116-122.

Hill, P. C., Pargament, K. I., Hood, R. W., McCullough Jr, M. E., Swyers, J. P., Larson, D. B., and Zinnbauer, B. J. (2000). Conceptualizing religion and spirituality: points of commonality, points of departure Journal for the Theory of Social Behaviour, 30(1), 51-77.

Horton, P. E. and Hunt, C. L. (1984). Sociology, New York: McGraw-Hill

Khalid, S., \&Gilani, A. H. (2009). Distinctive cultural and geographical legacy of Bahawalpur, Pakistaniaat: A Journal of Pakistan Studies, 2(2), 1-17.

Khan, A. A. and Khan, K. (2015). Women's role in livestock economy of Cholistan desert, Pakistan, Global Journal of Human-Social Science Research, 15(3), pp.29-39

Khan, A. A., Rashid, Mussarat and Sarwar, Hinaz (2004). Socio-economic profile of Cholistani people: A geographic view, Journal of Social Sciences and Humanities, 2 (1),pp. 49-72

Klemm, D.E. (2004). Foreword. In: David Jasper (ed). The sacred desert: religion, literature, art and culture, Oxford: Blackwell Publishing, i.-iii 
Kohari, Alizeh (2015). Daily dawn, retrieved 10 June 2016, from

herald.dawn.com/special/cholistan/

Krok, D. (2008). The role of spirituality in coping: Examining the relationships between spiritual Dimensions and coping styles, Mental health, religion and culture, 11(7), 643-653.

LeCompte, M. D., and Schensul, J. J. (2010). Designing and conducting ethnographic research: An introduction. New York: Rowman \& Littlefield Publishers.

Lane, B.C. (1998). The solace of fierce landscapes: exploring desert and mountain spirituality, Oxford: Oxford University Press.

McDowell, L. (1999). Gender, identity and place: understanding feminist geographies, Cambridge: Polity Press

Mughal, M. R. (1994). The Harappan nomads of Cholistan. In: Bridget Allchin (ed.). Living traditions: studies in the ethnoarchaeology of South Asia, New Delhi, Bombay and Calcutta: Oxford and IBH Publishing, 53-68.

Narayanan, Yamini and Macbeth, Jim (2009). Deep in the desert: merging the desert and the spiritual through 4WD tourism, Tourism geographies, 11 (3), 369-389, DOI: $10.1080 / 14616680903032783$

Oxhandler, H. K., \& Pargament, K. I. (2014). Social work practitioners' integration of clients' religion and spirituality in practice: a literature review, Social work, 59(3), 271-279

Population Bureau of Statistics, Population Distribution by Religion, 1998 Census (PDF). Pakistan Bureau of Statistics. Retrieved 07 June 2017 from

http://www.pbs.gov.pk/content/populationcensus

Pulla V. 2013. 'Coping and Resilience: Peoples Innovative Solutions'. International Journal of Innovation, Creativity and Change, Vol. 1 (1): 19. www.ijicc.net

Pulla, V. (2014). Spiritually sensitive social work: the road worth taking, chapter 10. In: B. R. Nikku and Z. A. Hatta (Eds.), Social work education and practice: scholarship and innovations in the Asia Pacific. Brisbane: Primrose Hall, 194-212

Pulla, V. and Mamidi, B.B. (2015). Emergence of resilience in the context of community empowerment, International Journal of Social Work and Human Services Practice, 3, 176 182. doi: 10.13189/ijrh.2015.030503.

Pulla, Venkat(2017). Desert spaces, people, and spirituality, Australian Catholic University (work in progress)

Robben, A. C. G. M., \& Sluka, J. A. (2007). Ethnographic fieldwork: An anthropological reader. Malden, MA: Blackwell Pub.

Singh, S. (2005). Secular pilgrimages and sacred tourism in the Indian Himalayas, GeoJournal, 64, 215-223.

Singh, S. B. (2015a). Women as milieu managers in integrated watershed management: perspectives from the hilly areas of Uttarakhand, Journal Space and Culture, India, 2(4), 71-79, DOI: http://dx.doi.org/10.20896/saci.v2i4.130

Singh, S. (2015b). Increased burden on women and male out-migration: an analysis of Khul Gad Micro watershed of the Kumoun Himalaya, International Journal of Social Work and Human Services Practice, 3(3), 118-123, DOI: 10.13189/ijrh.2015.030303

Singh S. (2014). Women, environment and sustainable development: a case study of Khul Gad Micro watershed of Kumoun Himalaya, Journal Space and Culture, India, 1(3), 53-64, DOI: http://dx.doi.org//10.20896/saci.v1i3.45

Shoukat, A. (2016). Socio economic roles of women in Cholistan: a study in social change, Unpublished PhD Thesis, Islamia University of Bahawalpur, Pakistan.

Soharwardi, M. A., Ali, K. and Arshad, M., Migration of Cholistani People from Desert areas toward Irrigated areas: Causes and Consequence (A Case Study of Cholistan, Pakistan). Int. J. Soc. Sci. Edu., 1, (3): 262-271. 2011. 
Tacey, D. (2003).The spirituality revolution: the https://newpakhistorian.wordpress.com/tag/ch emergence of contemporary spirituality, annar/

Sydney: Harper Collins Publishers

Zapf, M. K. (2005). The spiritual dimension of

Wordpresscom.

(2017).Wordpresscom. person and environment perspectives from Retrieved 22 June 2017, from social work and traditional knowledge, International Social Work, 48(5), 633-642. 